\title{
Post-Traumatic Stress Reaction Factors in Individuals Quarantined Due to Contact with COVID-19 Infected Individuals
}

Shatha Jamil Khusaifan ${ }^{1,2^{*}}$

${ }^{1}$ Department of Psychology, Faculty of Arts and Humanities, King Abdulaziz University, Jeddah, Saudi Arabia ${ }^{2}$ The Vice of Jeddah University for Women's Campus, Saudi Arabia

\section{Abstract}

During the COVID-19 pandemic, many individuals have been quarantined due to their contact with someone infected with the disease and some have experienced psychological stress reactions as a result. This study aims to explore factors affecting the psychological health and post-traumatic stress reactions in people quarantined due to COVID-19 in the Kingdom of Saudi Arabia. Participants included an experimental group of 450 quarantined individuals and a control group of 594 non-quarantined individuals. Participants completed measures of post-traumatic stress reactions, emotional regulation, general self-rated health, and multi-dimensional scales of perceived social support, stigma, and interpersonal avoidance. Significant differences in measures were found between the quarantined and the non-quarantined groups with respect to intrusion, avoidance, hyperarousal, PTSD, degree of emotional regulation, stigma, interpersonal avoidance, and general self-rated health. Overall, our results support the hypothesis that enforced quarantine during the COVID-19 pandemic is a significant determinant of psychological effects in individuals, including post-traumatic stress reactions.

\section{Introduction}

The coronavirus disease 2019 (COVID-19) pandemic is a major global health threat and crisis. COVID-19 is highly contagious and has impacted the lives of virtually everyone on the planet. The disease first appeared in the City of Wuhan and has spread beyond China to more than 210 countries [1]. Due to the gravity of the situation, the world has changed in dramatic ways to stem the spread of the disease. Social distancing, quarantining, and isolation started to be practiced at the beginning of April, 2020 in an attempt to reduce the spread of the disease, along with contact tracing to track those who had come in contact with an infected person [2]. Social distancing means people are to keep at least two arms' length distance from other people who are not members of their households, both indoors and outdoors. Quarantining is an enforced separation from all others and has been mandated for those who have had physical contact with an infected person or persons. Quarantine allows the person's COVID-19 status to be ascertained and decreases the chance of that person spreading the virus to others [3]. Quarantine is different from isolation, which, strictly speaking, is the seclusion of an infected person from uninfected individuals, even in one's own home. However, due to the global shutdown and stay-at-home orders, many others are experiencing social isolation. Saudi Arabia has been intensely vigilant and has implemented strict guidelines about remaining in one's home and quarantining [4]. As of this writing, Saudi Arabia has already recorded 354,813 confirmed cases of COVID-19 [1].

Although these strategies may help prevent the spread of infection, Pfefferbaum and North [5] have questioned whether there might be increased psychological risks in the population experiencing these restrictions. Being in quarantine can be inconvenient, problematic, and stressful. Separation from family members, confusion about one's COVID-19 status, and fatigue may trigger drastic negative consequences. Rubin and Wessely's [6] research on quarantining following indirect or direct contact with a person infected with COVID-19 assessed adverse consequences of the practice on an individual's mental health. They included measures of depression, boredom, stigma, and irritability. Psychological problems have been documented in the literature relating to previous epidemics [7]. COVID-19 has been studied in terms of its spread and prevention worldwide [1] but the psychological effects of being under quarantine in a state of confusion regarding one's health have not yet been studied in the Saudi context. An individual's emotional reactions and mental consequences following quarantine due to COVID-19 have not yet been studied either [8]. This study will help us understand factors linked to Post Traumatic Stress Disorder (PTSD) in those who have experienced quarantine due to contact with COVID-19-infected individuals. Additionally, this research will provide the scientific community with ethnically relevant data regarding the psychological response to quarantining among Saudi citizens, whether they might have experienced quarantine or not.

As quarantine is considered one of the foremost requirements for controlling the spread of COVID-19 [6], the WHO [1] recommends a speedy evaluation of the practice so that public health and safety can be ensured with minimal psychological risk. Certainly, a symptomatic person who experiences quarantine can experience stress. Initially, there is their anxiety and concern about developing the disease. Then, if they indeed develop the disease, they may fear the risk of dying; they can also be nervous about exposing others to COVID-19 and thereby harming them. Such symptomatic persons can experience profound stress levels even after quarantine [9].

PTSD is a common pathological consequence of traumatic events that can eventuate in wartime or disasters or individual circumstances, such as work problems or traffic accidents [10]. Patients who experience PTSD spend their life under the shadow of past trauma. PTSD covers a wide range of symptoms experienced by an individual after a severely stressful event. The Diagnostic and Statistical Manual of Mental Disorders of the American Psychiatric Association [11] list score

"Corresponding Author: Dr. Shatha Jamil Khusaifan, Department of Psychology Faculty of Arts and Humanities, King Abdulaziz University, P.O. Box 42803, Jeddah 21551, Saudi Arabia; E-mail: dr.shatha@hotmail.com

Citation: Khusaifan SJ (2021) Post-Traumatic Stress Reaction Factors in Individuals Quarantined Due to Contact with COVID-19 Infected Individuals. Int J Psychol Behav Anal 7: 178. doi: https://doi.org/10.15344/2455-3867/2021/178

Copyright: (C) 2021 Khusaifan. This is an open-access article distributed under the terms of the Creative Commons Attribution License, which permits unrestricted use, distribution, and reproduction in any medium, provided the original author and source are credited. 
symptoms, which include persistent intrusional thoughts, avoidance of stimuli, and negative and marked alterations in cognition or mood in both arousal or reactivity. PTSD causes clinically significant distress in social, occupational, or functional domains [11]. Moreover, PTSD is considered as an official diagnosis involving more intense, severe, and continued symptoms. At least six months must pass from the traumatic event to adequately diagnose this disorder. Identifying the factors associated with PTSD reactions is vital for preventing further complicated symptoms [12].

According to Mak et al. [13], there are observed factors that can play a significant role in affecting a person's life following an infectious disease pandemic. The most important predictive factor for PTSD after experiencing a pandemic is the level of exposure to the traumatic event. Being female, older, with a lower educational level and poor financial status are critical factors for PTSD. The presence of chronic mental or somatic conditions or illnesses, a neurotic personality, poor social connections, and a low level of social support are possible risk factors. Early psychosocial interventions can play a role as possible protective factors for PTSD [13].

Conrad [14] also described factors related to an individual's mental health that are likely to play a role during the COVID-19 pandemic. These include worrying about maintaining employment status, being tested for COVID-19, being diagnosed with the disease, and being stigmatized as a COVID-19 patient. They also include being in quarantine with uncertainty and confusion about the status of one's illness and prognosis. Other factors relate to rapid changes in daily routines, such as a student experiencing different levels of difficulties in academic life related to the closure of universities and attending classes remotely. Workers may experience a shift in their mode of work. And all individuals have experienced the ramifications of the global lockdown. These drastic changes are sufficient to make individuals vulnerable to the psychological effects of these wellness and mental health challenges [14]. Loneliness is also a risk factor for mental health problems, particularly for those experiencing isolation and quarantine. Domagala-Krecioch and Majerek [15] found that those younger than 25 years of age demonstrated high levels of loneliness.

Social support can be helpful for minimizing potential mental health risks, but it cannot be utilized in a normal fashion when people are told to stay at home, not to gather in large groups, not to gather indoors, and especially while in quarantine or isolation. Liu, Gayle, Wilder-Smith and Rocklöv [16] showed that an individual's resilience is helpful in coping with such mental stress. Being resilient is a major component of an individual's mental characteristics and enables the individual to manage and tolerate emotional stress and issues [16].

\section{Literature Review}

Much of the information available about the psychological effects of COVID-19 is insufficient in the Saudi context. However, researchers have made a few critical observations about the impact of a disease epidemic on residents who have experienced such lockdown conditions. They suggest that there are psychological consequences for an individual who experiences a traumatic event and help us understand some of the impacts. Le et al. [17] investigated the psychological impact of COVID-19 on the residents of Vietnam and explored associated factors on individuals in quarantine or social isolation. Their results indicated that $16.4 \%$ of individuals experienced low levels of post-traumatic stress (PTS) symptomatology, 5.3\% were rated as moderate, and 5.4\% reported extreme psychological symptoms. Females were found to have higher levels of psychological problems such as stress and other PTS-related reactions. Overall, a greater level of PTSD was found in females, the elderly, and children.

Similarly, research was carried out by Liu, Gayle, Wilder-Smith \& Rocklövin [16] to investigate the predictors of depression, PTSD symptomatology, anxiety, and stress in the U.S. population during the COVID-19 pandemic. Their results indicated that significant loneliness, worry specific to COVID-19, and low levels of tolerance for distress were significantly linked with clinical levels of depression, anxiety, and PTSD symptoms. Resilience was found with low levels of depression but not with PTSD; those who received high levels of social support were linked with low levels of PTSD and depression.

While some of the literature helps us understand that psychological impacts of COVID-19 exist, other studies help us understand the predictive factors for PTSD related to the COVID-19 pandemic. In this vein, the results of Crosta et al. [18] revealed that females in full-time employment with lower educational levels who did not previously live alone were more vulnerable to experiencing PTS symptoms than unemployed males with higher educational levels who previously lived alone.

Furthermore, some literatures studies help explore the psychological factors of PTSD in traumatic events that we can relate to COVID-19, its epidemic nature, and its painful consequences. Kukihara, Yamawaki, Uchiyama, Arai \& Horikawa [19] investigated the predictive role of resilience on mental and physical health after individuals experienced the traumatic events of Japan's mega earthquake and tsunami in 2011. Their results indicated that $53.5 \%$ demonstrated the diagnostic symptoms of PTSD, among whom $33.2 \%$ indicated clinical PTSD symptoms. Resilience was considered a significant protective factor for PTSD. Hussain, Weisæth \& Heir [20] conducted a longitudinal study to measure PTS symptoms after the 2004 Tsunami in the Indian ocean. They found a negative relationship between neuroticism and PTSD symptom improvement; individuals who reacted emotionally to stressful events had high levels of neuroticism.

Therefore, the literature does support us in identifying the factors affecting PTSD in those who are in quarantine after contact with COVID-19-infectedindividuals. Being in quarantine was a traumatic incident for them while they remained unaware of their COVID-19 status.

\section{Method}

\section{Study design and sample}

The study employed a comparative research design. The analysis was conducted on a sample whose respondents came from different geographical regions of Saudi Arabia. The sample size of 1044 comprised 594 control (non-quarantined) participants and 450 experimental (quarantined) participants, including both males and females. For comparison purposes, the participants included both those living in and not living in quarantine. This study excluded any person who exhibited signs of mental illness so that the results could be related specifically to PTSD.

\section{Measures}

Questionnaire-based surveys were used to obtain data from participants; a demographic form was used to collect participants' 
personal and sociodemographic data relating to gender, income level, employment status, age, and marital status. The Impact of Event Scale (IES-6) developed by Thoresen et al. in [21] was used to assess Post Traumatic Stress reactions (PTSR). This scale comprises six items related to intrusion, avoidance, and hyperarousal for assessing the reactions to life threat, traumatic loss, and witnessing experience. Cronbach's Alpha for the IES-6 was 0.80 .

An Arabic translation of the Emotion Regulation Questionnaire (ERQ) was used to measure participants' emotional regulation. This survey was developed by Gross and John [22]. Its self-report questionnaire of 10 items helped assess participants' emotional regression strategies of cognitive appraisal and emotional suppression. Responses were rated on a 5-point Likert-type scale ranging from $1=$ strongly disagree to $5=$ strongly agree. This scale has good internal consistency ranging from 0.785 to 0.754 .

General self-related health was assessed by using a single question from the General Self-Rated Health (GSRH) Questionnaire, SF-36:"In general, would you say your health is....” The responses on a 5-point Likert-type scale ranged from Excellent to Poor [23]. Values of 10, 9, 8,7 , and 6 , were assigned, respectively.

Factors of perceived social support were measured using a translated version of Zimet, Dahlem, Zimet, and Farley's [24] Multidimensional Scale of Perceived Social Support (MSPSS). The scale comprises 12 items, each ranging from $1=$ Very Strongly Disagree to $7=$ Very Strongly Agree. This questionnaire has three subscales measuring support from friends, family, and significant others. It has good internal and test retest reliability and moderate construct validity.

To assess participant perception of stigma and interpersonal avoidance, two items asked the question: "To what extent do you agree with the following statement?" These two items were: "I think that people will avoid me because of my quarantine," and "I think that people will avoid my family members because of my quarantine." Both items had a multiple-choice format with seven response options ranging from Not at all (1) to Too much (7).

\section{Procedures}

This study abided by the International Review Board's ethical guidelines. Ethical approval for conducting this study was obtained from the university. Before any data collection, the researcher mailed the authors and translators of the scales used to obtain permission for their use. The IES-6 and the single SF-36 question were translated by the study's author for indigenous purposes and were then backtranslated to ensure accuracy. Khusaifan and ElKeshky [25] translated the MSPSS. ElKeshky [26] established the validity of the ERQ translation.

The online questionnaires were sent only to those participants who fulfilled the criteria for inclusion in the study. Informed consent was taken by correspondence. The participants were told about the research's aims and objectives, that their confidentiality would be maintained, that their participation was voluntary, and that all the information would be used only for research purposes. Participants were asked to be as honest as possible when responding to the questions.

\section{Results}

This is a case-control study involving two groups of participants: those exposed to COVID-19-infected individuals and those who were not. The data collected from both groups were collated, coded, and analyzed using IBM SPSS Statistics v27. The results are presented below: the response rate and power analysis; the reliability and descriptive statistics; a comparative analysis of the key constructs for both groups; the hierarchical regression analysis; the main and interactive effects on PTSD in the case-control groups while controlling for the effects of the covariates, and finally a summary of the key findings.

\section{Power analysis}

A total of 1044 cases were collected, comprising 594 nonquarantined participants in the control group and 450 quarantined participants in the experimental group. No missing cases were observed among these responses; however, key outliers were observed beyond the prescribed range [LQ $\left.-1.5^{\star} \mathrm{IQR}, \mathrm{UQ} 3+1.5^{\star} \mathrm{IQR}\right][27,28]$. All outliers were redressed using the log transformation prescribed by Buuren [29] and Garson [30]. The post hoc sample power analysis was then carried out using $G^{*}$ Power to validate the sample's adequacy for the two main statistical analyses performed, that is, the ANCOVA and hierarchical linear regression [31]. This sought to determine the achieved sample power given the resultant effect size $\left(\mathrm{f}_{\mathrm{ANCOVA}}=0.170\right.$; $\left.f_{H L R}=0.321\right)$, sample size $(n=1044)$, and the significance level $(\alpha=$ $0.05)$. For the ANCOVA test, the noncentrality parameter was $\lambda=$ $20.172\left[\mathrm{~F}_{\text {crit }}(10,1035)=1.840\right]$ and the achieved power was 0.983 . For the hierarchical linear regression, which looked into the $\mathrm{R}^{2}$ increase for the effect of five additional tested predictors from a total of 35 predictors, the non centrality parameter was $\lambda=335.124\left[\mathrm{~F}_{\text {crit }}(5,1008)\right.$ $=2.223 \mathrm{~J}$ and the achieved power was 1.000. With both of these powers being greater than the prescribed minimum of 0.800 , the researcher confirmed that the sample size for this study was larger than the minimum required $[32,31]$.

\section{Demographic results}

The demographic data collected are presented in Table 1. Both groups had a larger proportion of females than males. The nonquarantined group was $64.8 \%$ women, and the quarantined was $76.2 \%$ women; this difference was statistically significant, $\chi^{2}(1)=128.483$, $\mathrm{p}<0.05$. Regarding the age groups, those between $30-39$ years of age dominated $(36.4 \%)$ the non-quarantined group and the $20-29$ year age group $(42.7 \%)$ dominated the quarantined group; this difference in ages was statistically significant, $\chi^{2}(4)=39.901, p<0.05$. With regard toethnicity, Saudi ethnics predominated in both samples at $92.9 \%$ for the non-quarantined group and $89.6 \%$ in the quarantined group; this difference was statistically significant, $\chi^{2}(2)=27.163 ; p<0.05$. There was no marked difference in frequencies by educational level; however, there were more post-graduate students among the nonquarantined respondents (36.9\%) than the quarantined ones $(27.6 \%)$; the comparison between groups was significant, $\chi^{2}(3)=12.077$; $\mathrm{p}<0.05$. For marital status, the modal category was married, with $59.1 \%$ in the non-quarantined group and $47.8 \%$ in the quarantined; there were more single status respondents in the quarantined group $(40.7 \%)$ than the non-quarantined $(30.8 \%)$. The difference by gender between the groups was statistically significant, $\chi^{2}(3)=14.948, p<0.05$.

The respondents also differed by employment status, with the majority of the non-quarantined group having a full-time job (55.6\%) and almost half of the quarantined group being unemployed (46.4\%); this difference was statistically significant, $\chi^{2}(3)=42.950, p<0.05$. Regarding monthly income, $44.9 \%$ of the non-quarantined group earned 11,000 Saudi Riyals and above, with a majority, 52.4\%, in
Int J Psychol Behav Anal

ISSN: 2456-3501
IJPBA, an open access journal Volume 7. 2021. 178 
Citation: Khusaifan SJ (2021) Post-Traumatic Stress Reaction Factors in Individuals Quarantined Due to Contact with COVID-19 Infected Individuals. Int J Psychol Behav Anal 7: 178. doi: https://doi.org/10.15344/2455-3867/2021/178

Page 4 of 9

that income bracket in the quarantined group; this difference was statistically significant, $\chi^{2}(5)=17.772, \mathrm{p}<0.05$. The average number of days in quarantine was $\mathrm{M}=6.72(\mathrm{SD}=3.882)$ for the quarantined group, which was statistically different from the non-quarantined group at 0 days, $\mathrm{t}(1042)=43.142, \mathrm{p}<0.05$. However, there was no statistically significant difference between groups in the average number of children; the rounded-up approximate was an average of two children, $\mathrm{t}(1042)=-1.864, \mathrm{p}>0.05$.

\section{Hierarchical linear regression analysis}

The first research objective sought to establish whether the degree of ERQ (cognitive reappraisal and expressive suppression), the level of stigma, the interpersonal avoidance, and the GSRH explained statistically significant variance in PTSD while controlling for all other explanatory variables [33]. The explanatory variables included in the base MODEL 1 comprise gender, income level, employment status, age, marital status, number of children, social support, and the number of days in quarantine. MODEL 2 adds the influence of the degree of ERQ, which was measured individually by cognitive reappraisal and expressive suppression, respectively. MODEL 3 measures the effect of the perceived level of stigma and interpersonal avoidance, while MODEL 4 measures the effect of the inclusion of the GSRH. The hierarchical regression model summary is shown in Table 2.

MODEL 1: In the non-quarantined group, the regression coefficient for the base model was 0.471 and its coefficient of determination was $\mathrm{R}^{2}=0.222$. In the quarantined group, the regression coefficient was 0.721 and the coefficient of determination was $\mathrm{R}^{2}=0.721$. This shows that gender, income level, employment status, age, marital status, number of children, social support, and the number of days in quarantine explained the greater variance in PTSD for the quarantined group than for the non-quarantined one. Thus, the predictive capacity of these variables was greater for the quarantined than the nonquarantined group.

\begin{tabular}{|c|c|c|c|c|c|c|}
\hline \multirow[t]{2}{*}{ Demographics } & \multirow[t]{2}{*}{ Group characteristics } & \multicolumn{2}{|c|}{ Not quarantined } & \multicolumn{2}{|c|}{ Quarantined } & \multirow[t]{2}{*}{$P$ value } \\
\hline & & Frequency & Percent & Frequency & Percent & \\
\hline \multirow[t]{2}{*}{ Gender } & Male & 209 & 35.2 & 107 & 23.8 & \multirow[t]{2}{*}{0.000} \\
\hline & Female & 385 & 64.8 & 343 & 76.2 & \\
\hline \multirow[t]{5}{*}{ Age } & $<20$ years & 6 & 1.0 & 9 & 2.0 & \multirow[t]{5}{*}{0.000} \\
\hline & $20-29$ years & 156 & 26.3 & 192 & 42.7 & \\
\hline & $30-39$ years & 216 & 36.4 & 143 & 31.8 & \\
\hline & $40-49$ years & 144 & 24.2 & 61 & 13.6 & \\
\hline & 50 years and above & 72 & 12.1 & 45 & 10.0 & \\
\hline \multirow[t]{3}{*}{ Ethnicity } & Saudi & 552 & 92.9 & 403 & 89.6 & \multirow[t]{3}{*}{0.000} \\
\hline & Arabic & 42 & 7.1 & 27 & 6.0 & \\
\hline & Non-Arabic & 0 & 0.0 & 20 & 4.4 & \\
\hline \multirow[t]{4}{*}{ Highest education level } & Left school & 6 & 1.0 & 9 & 2.0 & \multirow[t]{4}{*}{0.007} \\
\hline & High school & 72 & 12.1 & 71 & 15.8 & \\
\hline & Undergraduate degree & 297 & 50.0 & 246 & 54.7 & \\
\hline & Postgraduate degree & 219 & 36.9 & 124 & 27.6 & \\
\hline \multirow[t]{4}{*}{ Marital status } & Single & 183 & 30.8 & 183 & 40.7 & \multirow[t]{4}{*}{0.002} \\
\hline & Married & 351 & 59.1 & 215 & 47.8 & \\
\hline & Divorced & 54 & 9.1 & 43 & 9.6 & \\
\hline & Widowed & 6 & 1.0 & 9 & 2.0 & \\
\hline \multirow[t]{4}{*}{ Employment status } & Unemployed & 210 & 35.4 & 209 & 46.4 & \multirow[t]{4}{*}{0.000} \\
\hline & Part-time job & 18 & 3.0 & 43 & 9.6 & \\
\hline & Full-time job & 330 & 55.6 & 171 & 38.0 & \\
\hline & Retired & 36 & 6.1 & 27 & 6.0 & \\
\hline \multirow[t]{6}{*}{ Monthly income } & $<3000 \mathrm{SR}$ & 60 & 10.1 & 36 & 8.0 & \multirow[t]{6}{*}{0.003} \\
\hline & $3000-4999 \mathrm{SR}$ & 45 & 7.6 & 42 & 9.3 & \\
\hline & 5000-6999 SR & 48 & 8.1 & 47 & 10.4 & \\
\hline & 7000-8999SR & 72 & 12.1 & 45 & 10.0 & \\
\hline & 9000-10,999 SR & 102 & 17.2 & 44 & 9.8 & \\
\hline & $>11,000 \mathrm{SR}$ & 267 & 44.9 & 236 & 52.4 & \\
\hline Number of children & & \multicolumn{2}{|l|}{$1.66(1.761)$} & \multicolumn{2}{|l|}{$1.89(2.266)$} & 0.063 \\
\hline Days in quarantine & & \multicolumn{2}{|l|}{$0.00(0.000)$} & \multicolumn{2}{|l|}{$6.76(3.822)$} & 0.000 \\
\hline
\end{tabular}

Table 1: Demographic Results for Non-quarantined and Quarantined Groups.

SR is Saudi Riyals 
Citation: Khusaifan SJ (2021) Post-Traumatic Stress Reaction Factors in Individuals Quarantined Due to Contact with COVID-19 Infected Individuals. Int J Psychol Behav Anal 7: 178. doi: https://doi.org/10.15344/2455-3867/2021/178

Page 5 of 9

MODEL 2: With the inclusion of ERQ dimensions (cognitive reappraisal and expressive suppression), while controlling for the base variables, this model increased the predictive capacity of the model by $\Delta \mathrm{R}^{2}=0.003$ to $\mathrm{R}^{2}=0.474$ for the non-quarantined group and the quarantined group by $\Delta \mathrm{R}^{2}=0.074$ to $\mathrm{R}^{2}=0.594$. This change was not significant for the non-quarantined group, $\Delta \mathrm{F}(2,425)=38.536, \mathrm{p}<0.05$. In other words, cognitive reappraisal and/or expressive suppression had a significant effect on PTSD for the quarantined group but had no significant impact on PTSD for the non-quarantined one.
MODEL 3: The effect of stigma and interpersonal avoidance, while controlling for the base variables and preceding control variables, yielded a greater influence on the quarantined group, $\Delta \mathrm{R}^{2}=0.117$, $\mathrm{F}(2,423)=85.135, \mathrm{p}<0.05$, than on the non-quarantined one, $\Delta \mathrm{R}^{2}$ $=0.013, \mathrm{~F}(2,568)=43.395, \mathrm{p}<0.05$. With both of these results being statistically significant, it follows that stigma and/or interpersonal avoidance increased the variance in PTSD to a higher degree for the quarantined group than the non-quarantined one.

\begin{tabular}{|c|c|c|c|c|c|c|c|c|c|c|}
\hline \multirow[t]{2}{*}{ Quarantined? } & \multirow[t]{2}{*}{ Model } & \multirow[t]{2}{*}{$\mathrm{R}$} & \multirow[t]{2}{*}{$\mathrm{R} 2$} & \multirow[t]{2}{*}{ Adj. $\mathrm{R}^{2}$} & \multirow[t]{2}{*}{ SE } & \multicolumn{5}{|c|}{ Change statistics } \\
\hline & & & & & & $\Delta \mathrm{R}^{2}$ & $\Delta \mathrm{F}$ & $\mathrm{df1}$ & df2 & $\mathrm{p}(\Delta \mathrm{F})$ \\
\hline \multirow{4}{*}{$\begin{array}{l}\text { Non- } \\
\text { quarantined }\end{array}$} & 1 & .471 & .222 & .193 & 4.293 & .222 & 7.754 & 21 & 572 & .000 \\
\hline & 2 & .474 & .224 & .193 & 4.293 & .003 & .969 & 2 & 570 & .380 \\
\hline & 3 & .572 & .327 & .297 & 4.006 & .103 & 43.395 & 2 & 568 & .000 \\
\hline & 4 & .601 & .361 & .332 & 3.907 & .034 & 29.962 & 1 & 567 & .000 \\
\hline \multirow[t]{4}{*}{ Quarantined } & 1 & .721 & .520 & .495 & 3.525 & .520 & 21.019 & 22 & 427 & .000 \\
\hline & 2 & .770 & .594 & .571 & 3.250 & .074 & 38.536 & 2 & 425 & .000 \\
\hline & 3 & .843 & .710 & .692 & 2.751 & .117 & 85.135 & 2 & 423 & .000 \\
\hline & 4 & .843 & .711 & 692 & 2.752 & .001 & .821 & 1 & 422 & .366 \\
\hline
\end{tabular}

Table 2: Hierarchical Regression Model Summary.

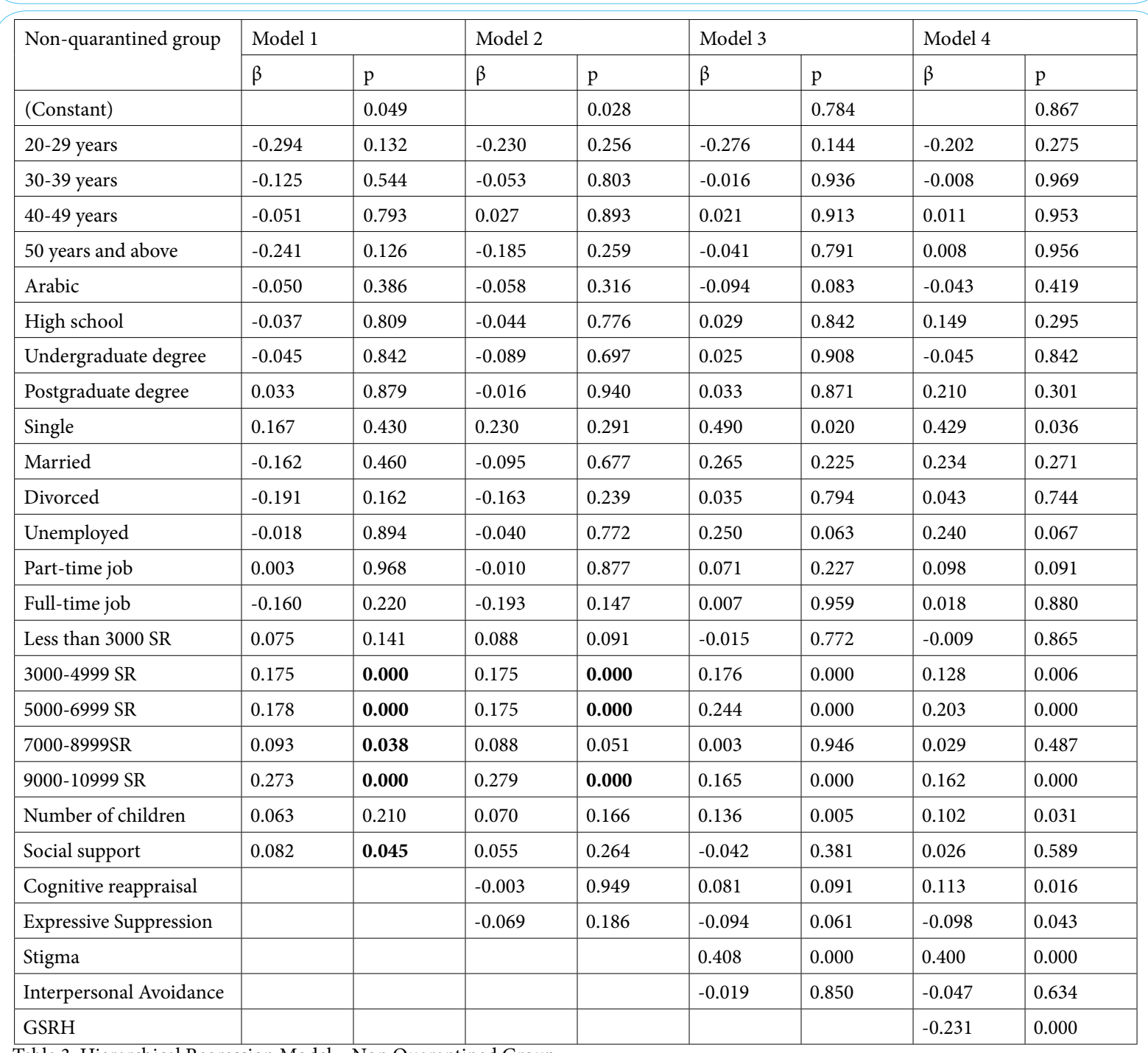

Table 3: Hierarchical Regression Model - Non Quarantined Group. 
Citation: Khusaifan SJ (2021) Post-Traumatic Stress Reaction Factors in Individuals Quarantined Due to Contact with COVID-19 Infected Individuals. Int J Psychol Behav Anal 7: 178. doi: https://doi.org/10.15344/2455-3867/2021/178

Page 6 of 9

MODEL 4: Lastly, contrary to the preceding model, the effect of GSRH while controlling for the base variables and preceding control variables yielded a greater influence on the non-quarantined group, with $\Delta \mathrm{R}^{2}=0.034, \mathrm{~F}(1,567)=29.962, \mathrm{p}<0.05$, than on the quarantined group, with $\Delta \mathrm{R}^{2}=0.001, \mathrm{~F}(2,422)=0.821, \mathrm{p}>0.05$. In other words, the GSRH had a significant effect on PTSD for the non-quarantined group but not for the quarantined group. Nevertheless, the final coefficient of determination was higher for the quarantined group $\left(\mathrm{R}^{2}\right.$ $=0.711)$ than the non-quarantined group $\left(\mathrm{R}^{2}=0.361\right)$.

Thus, with all the variables included, the greatest variation in PTSD resulted from the influence of the independent variables on the quarantined group, explaining $71.1 \%$ of the variance; the influence of the independent variables for the non-quarantined group explained only $36.1 \%$ of the variance in PTSD. The resultant hierarchical regression model for the non-quarantined group is shown in Table 3.

These results show that for the non-quarantined group, there was no statistically significant influence of age, ethnicity, highest level of education, marital status, employment status, and number of children on PTSD. The only significant base variables were income and social support. Cognitive reappraisal and expressive suppression (MODEL 2) were not statistically significant explanatory variables for PTSD after controlling for the base variables. For MODEL 3, only stigma had a statistically significant positive influence on PTSD; interpersonal avoidance did not. Lastly, for MODEL 4, the GSRH had a statistically significant negative relationship with PTSD. The effect of stigma and GSRH had a significant interaction effect with marital status for the single category only.

The corresponding hierarchical regression model for the quarantined group is presented in Table 4 .

Unlike the non-quarantined group, this group showed a statistically significant relationship between PTSD and age, ethnicity, the highest level of education, marital status, employment status, income, and the number of days in quarantine. Only the number of children and social support were not statistically significant factors.

Regarding MODEL 2, while cognitive reappraisal remains an insignificant factor (cf. the non-quarantined group), expressive suppression is now statistically significant with a positive effect.

\begin{tabular}{|c|c|c|c|c|c|c|c|c|}
\hline \multirow[t]{2}{*}{ Quarantined group } & \multicolumn{2}{|c|}{ Model 1} & \multicolumn{2}{|c|}{ Model 2} & \multicolumn{2}{|c|}{ Model 3} & \multicolumn{2}{|c|}{ Model 4} \\
\hline & $\mathrm{a}$ & $\mathrm{p}$ & $\beta$ & $\mathrm{p}$ & $\beta$ & $\mathrm{p}$ & $\beta$ & $\mathrm{p}$ \\
\hline (Constant) & & 0.000 & & 0.000 & & 0.000 & & 0.010 \\
\hline $20-29$ years & -1.012 & 0.000 & -0.878 & 0.001 & -0.535 & 0.016 & -0.428 & 0.088 \\
\hline $30-39$ years & -1.215 & 0.000 & -1.028 & 0.000 & -0.536 & 0.011 & -0.456 & 0.045 \\
\hline $40-49$ years & -0.793 & 0.000 & -0.734 & 0.000 & -0.411 & 0.002 & -0.351 & 0.019 \\
\hline 50 years and above & -0.933 & 0.000 & -0.772 & 0.000 & -0.258 & 0.073 & -0.179 & 0.288 \\
\hline Arabic & -0.749 & 0.000 & -0.769 & 0.000 & -0.720 & 0.000 & -0.708 & 0.000 \\
\hline Saudi & -0.455 & 0.000 & -0.359 & 0.000 & -0.463 & 0.000 & -0.475 & 0.000 \\
\hline High school & -0.282 & 0.000 & -0.223 & 0.000 & -0.313 & 0.000 & -0.309 & 0.000 \\
\hline Postgraduate degree & -0.105 & 0.040 & -0.028 & 0.562 & 0.040 & 0.331 & 0.039 & 0.343 \\
\hline Single & -0.831 & 0.000 & -0.786 & 0.001 & -0.138 & 0.499 & -0.038 & 0.870 \\
\hline Married & -0.992 & 0.000 & -1.149 & 0.000 & -0.418 & 0.045 & -0.314 & 0.187 \\
\hline Divorced & -0.467 & 0.002 & -0.580 & 0.000 & -0.115 & 0.387 & -0.039 & 0.807 \\
\hline Unemployed & -0.621 & 0.000 & -0.337 & 0.031 & 0.263 & 0.088 & 0.296 & 0.062 \\
\hline Part time job & -0.384 & 0.001 & -0.354 & 0.001 & 0.029 & 0.784 & 0.044 & 0.688 \\
\hline Full time job & -0.609 & 0.000 & -0.406 & 0.011 & 0.016 & 0.916 & 0.060 & 0.709 \\
\hline$<3000 \mathrm{SR}$ & -0.112 & 0.062 & -0.140 & 0.012 & -0.028 & 0.556 & -0.018 & 0.713 \\
\hline 3000-4999 SR & 0.211 & 0.000 & 0.125 & 0.014 & 0.020 & 0.637 & 0.012 & 0.796 \\
\hline 5000-6999 SR & -0.153 & 0.001 & -0.258 & 0.000 & -0.269 & 0.000 & -0.277 & 0.000 \\
\hline 7000-8999SR & 0.075 & 0.179 & 0.134 & 0.010 & -0.153 & 0.004 & -0.167 & 0.002 \\
\hline 9000-10999 SR & -0.129 & 0.007 & -0.202 & 0.000 & -0.226 & 0.000 & -0.229 & 0.000 \\
\hline Number of children & 0.003 & 0.977 & 0.197 & 0.065 & 0.120 & 0.184 & 0.145 & 0.125 \\
\hline Social support & 0.073 & 0.090 & 0.060 & 0.191 & -0.096 & 0.021 & -0.120 & 0.015 \\
\hline Days in quarantines & 0.191 & 0.000 & 0.128 & 0.002 & 0.053 & 0.146 & 0.054 & 0.138 \\
\hline Cognitive reappraisal & & & -0.003 & 0.958 & -0.115 & 0.025 & -0.115 & 0.025 \\
\hline Expressive Suppression & & & 0.370 & 0.000 & 0.506 & 0.000 & 0.510 & 0.000 \\
\hline Stigma & & & & & 0.794 & 0.000 & 0.810 & 0.000 \\
\hline Interpersonal Avoidance & & & & & -0.529 & 0.000 & -0.543 & 0.000 \\
\hline GSRH & & & & & & & 0.046 & 0.366 \\
\hline
\end{tabular}

Table 4: Hierarchical Regression Model - Quarantined Group. 
Citation: Khusaifan SJ (2021) Post-Traumatic Stress Reaction Factors in Individuals Quarantined Due to Contact with COVID-19 Infected Individuals. Int J Psychol Behav Anal 7: 178. doi: https://doi.org/10.15344/2455-3867/2021/178

Page 7 of 9

The inclusion of stigma and interpersonal avoidance in MODEL 3 while controlling for the preceding variables, also yielded statistically significant results, negative for interpersonal avoidance and positive for stigma. A significant interaction effect between stigma/ interpersonal avoidance and cognitive reappraisal and social support on PTSD also occurred. However, the GSRH in MODEL 4 did not have a statistically significant relationship with PTSD. The effect of stigma and GSRH had a significant interaction effect with marital status for the single category only.

\section{Analysis of covariance (ANCOVA)}

Whereas the first objective of this research was to establish the effects of COVID-19 quarantining on PTSD, the second objective was a follow-up analysis. The first objective was met when Table 4 established that the level of PTSD was significantly higher among individuals who had been exposed to COVID-19 than those who had not been exposed. Nevertheless, the earlier analysis did not account for the effect of covariate factors and to address this, according to Hox [34], Chapman and Feit [35], and Heck and Thomas [36], the analysis of covariances (ANCOVA) is the optimal approach.

In order to validate the testing of ANCOVA for the data collected, three important assumptions were tested. The first was the normality of residuals; the second was heteroscedasticity, while the last was the equality of error variances. None of these assumptions were violated and ANCOVA was considered suitable for the data. The results are presented in Table 5.

These results confirm that, after controlling for the effects of all the covariate factors, COVID-19 exposure and quarantine, the main grouping variable between the control group and the experimental group had a statistically significant positive impact on PTSD, F(1, $1044)=4.892, \mathrm{p}<0.05$. Other than this variable, the greatest influence on PTSD was stigma, $\mathrm{F}(1,1042)=76.634, \mathrm{p}<0.05$; the second greatest influence was GSHR, $\mathrm{F}(1,1044)=53.714, \mathrm{p}<0.05$; the third significant factor was interpersonal avoidance, $\mathrm{F}(1,1044)=35.903$, $\mathrm{p}<0.05$. The other factors that had significant main effects on PTSD were expressive suppression, social support, quarantine days, gender, age, ethnicity, education level, marital status, and employment status. However, cognitive reappraisal, the number of children, and income did not have significant main effects on PTSD.

\section{Discussion}

This study aimed to investigate factors affecting PTSD in those quarantined after contact with COVID-19-infected individuals and compare them with non-quarantined individuals. It was hypothesized that the level of PTSR would be greater in quarantined than in nonquarantined individuals. Stress reactions such as intrusion, avoidance, and hyperarousal may develop after exposure to traumatic events but being in quarantine during COVID-19 can itself feel threatening. These reactions also depend on when the person started perceiving quarantine as a personal assault [37]. Our findings are consistent with the literature that indicated higher levels of stress reactions were present in quarantined individuals [37]. Furthermore, our findings were consistent with our hypothesis that respondents living in quarantine would have higher scores for emotional regulation, such as expressive suppression, than those not quarantined. Our results suggested that emotional suppression has more significant links with quarantined than non-quarantined individuals. The literature revealed

\begin{tabular}{|c|c|c|c|c|c|c|c|}
\hline & SS & $\mathrm{df}$ & MS & $\mathrm{F}$ & Sig. & $\eta^{2}$ & Power \\
\hline Corrected model & $84146.742^{\mathrm{a}}$ & 16 & 5259.171 & 26.870 & .000 & .295 & 1.000 \\
\hline Intercept & 2033.024 & 1 & 2033.024 & 10.387 & .001 & .010 & .896 \\
\hline Cognitive reappraisal & 91.085 & 1 & 91.085 & .465 & .495 & .000 & .105 \\
\hline Expressive suppression & 5351.390 & 1 & 5351.390 & 27.341 & .000 & .026 & .999 \\
\hline Social support & 2615.020 & 1 & 2615.020 & 13.361 & .000 & .013 & .955 \\
\hline Stigma & 14999.159 & 1 & 14999.159 & 76.634 & .000 & .069 & 1.000 \\
\hline Interpersonal avoidance & 7027.038 & 1 & 7027.038 & 35.903 & .000 & .034 & 1.000 \\
\hline GSRH & 10513.219 & 1 & 10513.219 & 53.714 & .000 & .050 & 1.000 \\
\hline Children & 31.830 & 1 & 31.830 & .163 & .687 & .000 & .069 \\
\hline Quarantine days & 924.180 & 1 & 924.180 & 4.722 & .030 & .005 & .584 \\
\hline Gender & 2113.224 & 1 & 2113.224 & 10.797 & .001 & .010 & .907 \\
\hline Age & 1267.227 & 1 & 1267.227 & 6.475 & .011 & .006 & .720 \\
\hline Ethnicity & 5753.349 & 1 & 5753.349 & 29.395 & .000 & .028 & 1.000 \\
\hline Education & 2710.525 & 1 & 2710.525 & 13.849 & .000 & .013 & .961 \\
\hline Marital & 6712.968 & 1 & 6712.968 & 34.298 & .000 & .032 & 1.000 \\
\hline Employment & 2456.644 & 1 & 2456.644 & 12.551 & .000 & .012 & .943 \\
\hline Income & 5.633 & 1 & 5.633 & .029 & .865 & .000 & .053 \\
\hline COVID-19 quarantine & 957.508 & 1 & 957.508 & 4.892 & .027 & .005 & .599 \\
\hline Error & 201009.953 & 1027 & 195.725 & & & & \\
\hline Total & 1112900.000 & 1044 & & & & & \\
\hline Corrected total & 285156.694 & 1043 & & & & & \\
\hline
\end{tabular}

Table 5: ANCOVA - Tests of Between-Subjects Effects.

${ }^{\mathrm{a}} \mathrm{R}$ Squared $=.295$ (Adjusted R Squared $=.284$ ). 
Citation: Khusaifan SJ (2021) Post-Traumatic Stress Reaction Factors in Individuals Quarantined Due to Contact with COVID-19 Infected Individuals. Int J Psychol Behav Anal 7: 178. doi: https://doi.org/10.15344/2455-3867/2021/178

Page 8 of 9

that suppression related to emotions might contribute to PTSR and eventually to chronic PTSD [38]. Although expressive suppression is related to the physiological response to a stressful situation, that might be intensified or prolonged by expressive suppression [39]. Exposure to traumatic events is a factor that can lessen emotional regulation capacity, which prolongs the difficulties in emotion regulation $[40,41]$.

Further, it was hypothesized that the GSRH of quarantined individuals would be lower than for the non-quarantined. Our results supported this hypothesis as well. Social isolation, such as being in quarantine and lacking social support, is considered an acute and chronic stressor that can affect an individual's general health. It can also increase the level of unhealthy behaviors [42,43]. Our findings are consistent with previous research indicating an increased level of social support can be linked with good GSRH [44].

Furthermore, it was hypothesized that stigmatization levels would be higher in quarantined than non-quarantined individuals. Our findings also indicated this and are consistent with the literature. Bai et al. [45] found that quarantined participants were significantly more likely to report stigmatization and experience rejection from other people. In several studies, respondents living in quarantine reported that others avoided them or treated them with fear and suspicion and also made critical comments [45].

Our results supported our hypothesis that age can be a significant predictor of PTSD reactions in individuals quarantined after contact with COVID-19 patients. While the findings indicated that age is a significant predictor of PTSD reactions in both quarantined and nonquarantined individuals, the age factor is more prominent in those who experience quarantine. This might be because age is significantly linked with the volume of their brain's amygdala. Those who respond to the stress might have a smaller or larger amygdala than those who don't experience such age-related stress reactions. Our findings are consistent with the stress responsivity model, which suggests that the age-related reaction to stress is significantly linked with age-related amygdala growth [46].

Our findings supported the hypothesis that quarantined individuals have higher levels of PTSR than the non-quarantined based on the demographic factor of identity. Our findings are consistent with the literature, which suggests that identity can be a significant factor in PTSD reactions [47]. This hypothesis is further supported by the model of identity change, which states that social identity can play a predictive role when experiencing a traumatic event. Identity can facilitate PTSR; resilient identity can suppress stressful reactions [48].

Finally, our results supported the hypothesis that quarantine duration is significantly linked with PTSR. Our findings are consistent with the previous literature stating that longer quarantine time may exaggerate traumatic stress reactions [37].

\section{Implications of the study}

The data from this study will support health authorities in gaining insight into advisable, appropriate measures for more successful and sustainable enforcement of national quarantines. The data can inform official health communications and public awareness campaigns about the factors associated with PTSD. Thus, the use of control measures can more effectively increase compliance among citizens and increase their capacity to cope emotionally and psychologically with quarantine. Mental health counselors will also find this study helpful in their therapeutic processes.

\section{Limitations of the Study}

Several limitations were present in this research that could affect its interpretation. The study's respondents did not represent the entire population of Saudi Arabia. Due to limited responses, the study did not examine individuals less than 19 years old or older than 55 . Moreover, the data was collected by email because of COVID-19 and the need to follow strict government guidelines about social distancing. As a result, individuals without internet access or social media accounts, computers, or cell phones could not participate. The Arabic language was used in the research, so non-Arabic speakers could not participate in the study. Consequently, the findings of this data cannot be generalized to the overall population of Saudi Arabia. Additionally, the surveys were completed on a self-report basis, which has limitations because there is a chance of misinterpretation of the questions. Future studies are needed to account for these limitations.

\section{Conclusion}

Our aim was to investigate factors affecting PTSR in quarantined individuals who had been in contact with a COVID-19 patient and to determine the differences in such reactions between quarantined and non-quarantined individuals in the Saudi population, using multiple variables identified as risk factors, such as age, identity, emotional regulation, and general self-related health.

We suggest that the Ministry of Health implement new policies and procedures to take those risk factors into account, especially for vulnerable groups of quarantined individuals. Doing so will be a step toward minimizing the psychologically negative impact of the COVID-19 pandemic on the Saudi population.

\section{Competing Interests}

The author declare that there is no competing interests regarding the publication of this article.

\section{References}

1. World Health Organization (2020) Coronavirus disease 2019 (COVID-19) Situation Report - 88

2. Parmet WE, Sinha MS (2020) Covid-19 - The law and limits of quarantine. N Engl J Med 382: e28-e28.

3. Centers for Disease Control and Prevention (2020) Quarantine and isolation.

4. Wu Z, McGoogan JM (2020) Characteristics of and important lessons from the coronavirus disease 2019 (COVID-19) outbreak in China: Summary of a report of 72314 cases from the Chinese Center for Disease Control and Prevention. JAMA 323: 1239-1242.

5. Pfefferbaum B, North CS (2020) Mental health and the Covid-19 pandemic. N Engl J Med 383: 510-512.

6. Rubin GJ, Wessely S (2020) The psychological effects of quarantining a city. BMJ 368: m313.

7. Barbisch D, Koenig KL, Shih FY (2015) Is there a case for quarantine? Perspectives from SARS to Ebola. Disaster Med Public Health Prep 9: 547553.

8. Wilder-Smith A, Chiew CJ, Lee VJ (2020) Can we contain the COVID-19 outbreak with the same measures as for SARS? Lancet Infect Dis 20: E102-E107.

9. Brooks SK, Webster RK, Smith LE, Woodland L, Wessely S, et al. (2020) The psychological impact of quarantine and how to reduce it: rapid review of the evidence. Lancet 395: 912-920. 
Citation: Khusaifan SJ (2021) Post-Traumatic Stress Reaction Factors in Individuals Quarantined Due to Contact with COVID-19 Infected Individuals. Int J Psychol Behav Anal 7: 178. doi: https://doi.org/10.15344/2455-3867/2021/178

Page 9 of 9

10. Shalev AY, Marmar CR (2017) Post-traumatic stress disorder. In Sadock BJ, Sadock VA, Ruiz P (Eds.), Kaplan and Sadock's comprehensive textbook of psychiatry.

11. American Psychiatric Association (2013) Diagnostic and statistical manual of mental disorders.

12. Fawaz M, Samaha A (2020) COVID-19 quarantine: Post-traumatic stress symptomatology among Lebanese citizens. International Journal of Social Psychiatry 66: 666-674.

13. Mak IWC, Chu CM, Pan PC, You MGC, Ho SC, et al. (2010) Risk factors for chronic post-traumatic stress disorder (PTSD) in SARS survivors. Gen Hosp Psychiatry 32: 590-598.

14. Conrad R (2020) Universities' response to supporting mental health of college students during the COVID-19 pandemic. Psychiatric Times.

15. Domagala-Krecioch A, Majerek B (2013) The issue of loneliness in the period of "emerging adulthood." European Scientific Journal, SPECIAL/edition.

16. Liu Y, Gayle AA, Wilder-Smith A, Rocklöv J (2020) The reproductive number of COVID-19 is higher compared to SARS coronavirus. J Travel Med 27: 21 .

17. Le XTT, Dang AK, Toweh J, Nguyen QN, Le HT, et al. (2020) Evaluating the psychological impacts related to COVID-19 of Vietnamese people under the first nationwide partial lockdown in Vietnam. Front Psychiatry 11: 824.

18. Crosta DA, Palumbo R, Marchetti D, Ceccato I, Malva PL, et al. (2020) Individual differences, economic stability, and fear of contagion as risk factors for PTSD symptoms in the COVID-19 emergency. Front Psychol 11: 567367.

19. Kukihara H, Yamawaki N, Uchiyama K, Arai S, Horikawa E, et al. (2014) Trauma, depression, and resilience of earthquake/tsunami/nuclear disaster survivors of Hirono, Fukushima, Japan. Psychiatry Clin Neurosci 68: 524-533.

20. Hussain A, Weisæth L, Heir T (2013) Posttraumatic stress and symptom improvement in Norwegian tourists exposed to the 2004 tsunami - a longitudinal study. BMC Psychiatry 13: 232.

21. Thoresen S, Tambs K, Hussain A, Heir T, Johansen V, et al. (2009) Brief measure of posttraumatic stress reactions: Impact of Event Scale-6. Social Psychiatry \& Psychiatric Epidemiology 45: 405-412.

22. Gross JJ, John OP (2003) Individual differences in two emotion regulation processes: Implications for affect, relationships, and well-being. J Pers Soc Psychol 85: 348-362.

23. DeSalvo KB, Bloser N, Reynolds K, He J, Muntner P, et al. (2006) Mortality prediction with a single general self-rated health question. A meta-analysis. J Gen Intern Med 21: 267-275.

24. Zimet GD, Dahlem NW, Zimet SG, Farley GK (1988) The multidimensional scale of perceived social support. Journal of Personality Assessment 52: 3041.

25. Khusaifan S, El-Keshky M (2017) Social support as a mediator variable of the relationship between depression and life satisfaction in a sample of Saudi caregivers of patients with Alzheimer's disease. Int Psychogeriatr 29: 239-248

26. El Keshky ME (2018) Factor structure, reliability and validity of the Arabic version of the Emotion Regulation Questionnaire (ERQ) in a sample of Saud children and adolescents. International Journal of Psychology \& Behavioral Sciences, 8, 22-30.

27. Raghunathan $T$ (2015) Missing data analysis in practice. CRC Press.

28. Field AP (2018) Discovering statistics using SPSS. SAGE.

29. Buuren S (2012) Flexible imputation of missing data. Chapman and Hall/ CRC

30. Garson GD (2012) Testing statistical assumptions. Statistical Associates Publishing.

31. Ahmad W (2018) Sample size calculation made easy using G*Power Penerbit USM.

32. Wywial JL (2015) Sampling designs dependent on sample parameters of auxiliary variables. Springer.

33. Finch WH, Bolin JE (2017) Multilevel Modeling Using Mplus. Taylor \& Francis Group.

34. Hox JJ (2013) Multilevel regression and multilevel structural equation modeling. The Oxford handbook of quantitative methods. Oxford University Press.
35. Chapman C, Feit EM (2015) R for marketing research and analytics. Springer.

36. Heck RH, Thomas SL (2015) An introduction to multilevel modeling techniques: MLM and SEM approaches using Mplus (3rd ed.). Routledge.

37. Breslau N, Kessler RC, Chilcoat HD, Schultz LR, Davis GC, et al. (1998) Trauma and posttraumatic stress disorder in the community: the 1996 Detroit Area Survey of Trauma. Arch Gen Psychiatry 55: 626-632.

38. Roemer L, Litz B, Orsillo S, Wagner A (2001) A preliminary investigation of the role of strategic withholding of emotions in PTSD. Journal of Traumatic Stress 14: 149-156.

39. Gross JJ (1988) Antecedent- and response-focused emotion regulation: Divergent consequences for experience, expression, and physiology. J Pers Soc Psychol 74: 224-237.

40. Frewen PA, Lanius RA (2006) Toward a psychobiology of posttraumatic selfdysregulation: reexperiencing, hyperarousal, dissociation, and emotional numbing. Ann N Y Acad Sci 1071: 110-124.

41. Garnefski N, Van den Kommer T, Kraaij V, Teerds J, Legerstee J, et al. (2002) The relationship between cognitive emotion regulation strategies and emotional problems: Comparison between a clinical and a non-clinical sample. European Journal of Personality 16: 403-420.

42. Cohen S (1988) Psychosocial models of the role of social support in the etiology of physical disease. Health Psychol 7: 269-297.

43. Berkman LF, Glass T, Brissette I, Seeman TE (2000) From social integration to health: Durkheim in the new millennium. Social Science \& Medicine 51: 843-857.

44. Yu H, Li M, Li Z, Xiang W, Yiwen Y, et al. (2020) Coping style, social support and psychological distress in the general Chinese population in the early stages of the COVID-19 epidemic. BMC Psychiatry 20: 426.

45. Bai $Y$, Lin CC, Lin CY, Chen JY, Chue CM, et al. (2004) Survey of stress reactions among health care workers involved with the SARS outbreak. Psychiatric Services 55: 1055-1057.

46. Del Giudice M, Ellis BJ, Shirtcliff EA (2011) The adaptive calibration model of stress responsivity. Neurosci Biobehav Rev 35: 1562-1592.

47. Haslam AS, Muldoon TO, Haslam C, Cruwys T, Kearns M, et al. (2019) The social psychology of responses to trauma: social identity pathways associated with divergent traumatic responses. European Review of Social Psychology 30: 311-348.

48. Joseph S, Linley PA (2006) Growth following adversity: Theoretical perspectives and implications for clinical practice. Clinical Psychology Review 26: 1041-1053. 